\title{
Prioritizing students' mobile centric information access needs: A case of Postgraduate students
}

\author{
Baldreck Chipangura \\ School of Computing \\ University of South Africa \\ Pretoria, South Africa \\ chipab@unisa.ac.za
}

\author{
Judy. A. van Biljon \\ School of Computing \\ University of South Africa \\ Pretoria, South Africa \\ vbiljja@unisa.ac.za
}

\author{
Adele Botha \\ CSIR \\ Pretoria, South Africa \\ a.botha@CSIR.co.za
}

\begin{abstract}
Students enrolled at Open and Distance Learning (ODL) institutions tend to combine study and work and to succeed they have to optimize free time for studying. Therefore, many ODL students access and interact with information in a mobile context, which implies that interaction takes place in dynamic and changing environments. This presents students with a number of overlapping contextual challenges that need to be managed when accessing and interacting with information. Higher Educational Institutions (HEIs) are also confronted by these challenges as they strive to provide access through technologies that are accessible, usable, scalable and sustainable to students. Against this background, it is important to have an understanding of the categories of information that students would want to access and interact with through the devices that they privately own, of which mobile phones are the most common. This study investigated the categories of information that students would want to access through mobile cellular phones. The data capturing involved both qualitative and quantitative data. In order to get a comprehensive and representative set of information access needs it was necessary to start with openended questions. Based on the analysis of the 50 responses to the open-ended questions, fixed-response questions were formulated. The 84 responses to the fixed-response questions were then analyzed to determine the importance of the information access needs as well as the access frequency. The contribution of this paper is a set of prioritized information needs that provide some insight into the mobile centric information needs of students at the University of South Africa (UNISA) as an example of an ODL institution.
\end{abstract}

Keywords-mobile phone, mobile phone acces, information access needs

\section{I.INTRODUCTION}

Open and Distance Learning students have a learning route that requires remote access and interaction with learning resources [1]. The success of the interaction between the students and their study resources can be affected by the dynamic and changing environments which ODL students occupy as they study. The ODL students tend to integrate academic and work related activities in order to utilize available time towards maximizing their academic pursuits [2]. In addition, ODL students tend to engage in academic pursuits in isolation. If not adequately supported the feelings of isolation can cause anxiety which can increase as a result of the limited interaction amongst students and their lecturers [3, 4]. In order to improve student support, the HEIs could communicate and provide resources through technologies owned by the students.
In developing countries, at most HEIs, communication and access to resources by the students is PC-centric. That means it is mostly facilitated and provided through a desktop computing platform. This PC centric orientation is in line with most HEIs' ICT policies and that of both academic and administrative employees [5]. On the other hand, the most common ICT resource owned by the students is a mobile phone [6]. Therefore, the provision of information and interaction strategies at HEIs may not match the mostly mobile centric student population. The consequence is a situation where students would not have sufficient access to content and services that the university supplies for their benefit [7]. The resulting disconnection between the way information is provided by HEIs and the way students can access it can be described as a digital difference [8].

Even though mobile phones can facilitate information access and interaction with university repositories, it is acknowledged that mobile phones cannot provide the same functionality as computers. Consequently, HEIs are faced with challenges in providing students with mobile cellular technology access to information and content. As the penetration of mobile devices continue to escalate it becomes imperative for HEI to understand information access needs of mobile phone primary users.

The aim of this paper is to contribute to the understanding of information access needs of mobile phone primary users. The following research question will guide the subsequent investigation:

What are the mobile phone information access and interaction needs of students at HEIs?

The remainder of this paper is organized as follows: section II presents a literature analyses, section III outlines the methodology, section IV presents the results, $\mathrm{V}$ presents a summary of mobile phone information needs and in conclusion, section VI discusses the implications and contributions of the paper.

\section{LITERATURE ANALYSIS}

An information access need is defined as the perceived requirement for information that motivates someone to use an information retrieval system in the first place [9]. The retrieval intent is not only informational but can include actions that are considered to be navigational, transactional [10] or to enable access to resources [11]. Therefore, there is a need to identify 
and prioritize the mobile information access and interaction needs of mobile phone primary users at HEIs in developing countries in order to provide institutional ICT services and resources that students can access and use.

There are two approaches to understanding user information needs. The first approach looks at what information users search for and how they search for that information [12]. Following this approach, analysis of literature on mobile phone information access and interaction found common activities to be based on social interaction, entertainment and business transactions [12-17].

The second approach examines why users search for information [18]. This second approach includes considerations related to the types of content that mobile users access. Some studies have extended their exploration to include the motivation behind mobile information access [1, 19, 20]. These motivations were found to be information seeking, communication, transaction and personal space extension [19].

Regarding personal mobile phone use of university students, two groups of spaces were identified, the core spaces, which a user expects to have, and the additional spaces that enhance user experience in using the mobile phone [1]. The core spaces were identified as: relationships, personal information, organization, safety, and security. The additional spaces were identified as: entertainment, m-commerce, expansion, non-personal information, personal history, and image. On contextualizing the usage spaces to m-learning, the core spaces were proposed to be information dissemination and academic communication, and the additional spaces were proposed as social communication and transactional [20].

Motives for mobile phone information access were also classified as utilitarian and hedonic [18]. Utilitarian motives are derived by the need to use mobile phones for convenience, restrictions at work, or computer occupied by someone else. Hedonic motives are a result of curiosity, social connection, and social avoidance.

Contextualizing the literature review analysis to mobile information access needs of students in higher education, the following categories have been identified from previous research: communication needs, access to resources and interaction needs [5]. These categories are now discussed in brief.

\section{A. Communication needs}

It can be argued that the primary use of a mobile phone is communication. At HEIs, mobile phone communication provides students and lecturers with a variety of communication channels which are either text based such SMS, Mxit, Whatsapp, Blackberry messenger and email or voice based channels. Mobile phones have been used for administrative communication such as sending SMS for class cancellation alerts, assignment due dates, exam results release alerts and general communication with students [21, 22]. Administrative uses of mobile phones have also been extended to managing safety and security emergencies at universities with two cases reported, one at the University of Louisiana [23], and the other at St. John's University in Queens, New
York [24]. In university libraries, mobile phones are used for sending SMS circulation alerts such as due date of borrowed books, availability of requested material and new resources [25]. These are just a few of the aspects where mobile phones can be used as a communication tool in HEIs.

\section{B. Access to resources needs}

Distance learning students access information on the move. Their changing context requires sporadic access to learning resources. Mobile cellular technology can facilitate this need. Resources that students can access through mobile phones include library resources, learning management system, reading material and podcasts [26-28].

\section{Interaction needs}

Literature reports several ways in which students can use mobile phones for interactions such as practical learning [29], group work [30], getting help [31], real time peer tutoring and assessment [32]. These are some of the few examples in which mobile phones can be used for interaction in distance learning.

The three categories outlined, communication needs, access to resources and interaction needs were identified from literature and underpins the analysis of the collected data.

\section{METHODOLOGY}

Mixed method research design was employed in the study to collect both qualitative and quantitative responses from students. The following sections discuss how the qualitative and quantitative data were gathered and analyzed.

\section{A. Qualitative component (open-ended responses)}

Students were asked to respond to an open ended questionnaire. The aim of the survey was to investigate students' information access to content and services at HEIs through mobile cellular technology. The questionnaire consisted of two questions but this paper is focused on one question namely: "What kind of information do students prefer to get through a mobile cellular phone?”

The target sample for the survey was 100 honours students registered for an E-learning course in the School of Computing. All the students responded to the survey but due to time restriction only 50 of the scripts were analyzed.

Framework Analysis [33] was used to analyze the collected data from the survey. The analysis process included familiarization, identifying a thematic framework, indexing, charting, mapping and interpretation.

The themes that emerged from the analysis were classified according to the categories identified from the literature review as communication needs, access to resources and interaction needs.

\section{B. Quantitative component (fixed responses)}

The limitation of using open-ended questions is that it cannot be used to empirically rate or prioritize categories. While the qualitative data and interpretation thereof was necessary to afford a comprehensive, rich and authentic set of student needs. The categories of needs that emerged from the qualitative survey were used to construct a quantitative 
questionnaire to prioritize the needs. The quantitative phase used fixed response questions to determine the importance of the needs that emerged from the qualitative phase.

The questionnaire consisted of four closed ended questions whose responses were rated on a five point Likert scale. This paper is focused on two of the questions, namely: "How would you rank the importance of each of the needs for implementing on a mobile phone information access system in an ODL environment?", and "How often would you access the need if it is implemented on a mobile phone information access system?” These questions were designed in a form of a matrix that listed the needs that were identified through the qualitative questionnaire.

The target sample of the survey was honours students registered for an e-learning course in the School of Computing. This group was purposively selected to provide an informed opinion on mobile information access since the elearning course addresses issues of m-learning. In total, 84 students responded to the survey.

The students' responses were statistically analyzed to prioritize the needs in terms of importance and frequency. The contribution of this paper is the set of prioritized student needs.

\section{IV.FINDINGS}

This section presents the findings under two sub-sections. Students' mobile phone information access needs based on the analysis of the open-ended questionnaire are presented in section $A$. In section $B$ the mobile phone information access needs are presented as a ranked set based on the analysis of the quantitative survey. The measures that were used to rank the mobile phone information access needs were importance of the need and frequency of access.

\section{A. Students' mobile phone information access needs}

From the analysis of students' responses to question one of the qualitative questionnaires, 20 themes emerged in response to the open ended questions posed. These 20 themes are grouped according to the categories identified from literature and presented in Table I. Frequencies of the themes were recorded as a percentage of the students who suggested the need.

From observation of Table 1, it can be seen that the category access to resources has nine needs, the communication category has six needs and the interaction category has only five needs. Each category is now discussed in more detail.

\section{1) Access to resources needs}

Nine themes of resources that students would like to access through mobile phones emerged, see Table I. The most popular resource was exam results (70\%). The resources that were least suggested by students were campus maps and directions (2\%), practice exam questions (2\%), and calendar and timetable (2\%). The students suggested that access to results should be facilitated through an interface that allows querying a database at anytime and anywhere.
TABLE I. MOBILE PHONE INFORMATION NEEDS

\begin{tabular}{|c|c|c|}
\hline Needs & $\begin{array}{l}\text { Students who } \\
\text { suggested the } \\
\text { need ( } \% \text { of } N \text { ) }\end{array}$ & Category of need \\
\hline Discussion forum & $58 \%$ & Interaction \\
\hline $\begin{array}{l}\text { Assignment submission } \\
\text { (Structured questions) }\end{array}$ & $8 \%$ & Interaction \\
\hline Self-assessment & $2 \%$ & Interaction \\
\hline MCQ assignments & $60 \%$ & Interaction \\
\hline Course feedback & $30 \%$ & Interaction \\
\hline Access to Exam results & $70 \%$ & Access to resources \\
\hline Access to students fees & $18 \%$ & Access to resources \\
\hline Study material & $16 \%$ & Access to resources \\
\hline Podcasts/Vodcasts & $10 \%$ & Access to resources \\
\hline Library access & $8 \%$ & Access to resources \\
\hline Lecture summaries & $6 \%$ & Access to resources \\
\hline Maps and directions & $2 \%$ & Access to resources \\
\hline Practice exam questions & $2 \%$ & Access to resources \\
\hline Calendar or timetable & $2 \%$ & Access to resources \\
\hline Announcements & $86 \%$ & Communication \\
\hline Due date reminders & $76 \%$ & Communication \\
\hline $\begin{array}{lll}\begin{array}{l}\text { Student } \\
\text { alerts }\end{array} & \text { results } & \text { release } \\
\end{array}$ & $74 \%$ & Communication \\
\hline Telephone conversation & $30 \%$ & Communication \\
\hline SMS messaging & $30 \%$ & Communication \\
\hline Registration date reminders & $8 \%$ & Communication \\
\hline
\end{tabular}

It emerged that students may not be interested in accessing bandwidth intensive resources through mobile phones such as study material. In this regard one student said, "Information that is smaller in size such as lecture notes summaries would be useful if they were to be accessed on mobile devices as these would be reviewed at the student's time"

When accessing resources, the need expressed by the students was for the queries to return concise responses rather than information intensive responses that require browsing through the university website. In this regard, one student said, "Students want to have access to relevant information. In many cases a whole lot of unrelated materials is mixed with the relevant material that students require and this causes problems when searching for information"

\section{2) Communication needs}

Six themes of needs emerged under administrative communication and they are: announcements (86\%), due date reminders (76\%), students' results release alerts (74\%), telephone conversation (30\%), SMS chatting (30\%) and registration dates reminders (8\%). Communication needs can be categorized into synchronous and asynchronous communication.

Themes that emerged from data analysis and provide students with synchronous communication were telephone conversation (30\%) and SMS messaging (30\%). The reasons why these synchronous communication needs were not very 
popular with students may be due to the fact that they have financial implications. SMS messaging was suggested as a communication means that would facilitate dialogue among students but not between students and lecturers. Students also proposed that they would like to receive multiple choice solutions to assignments through SMS.

Themes that fell under asynchronous communication were announcements, due date reminders, students results release alerts, and registration reminders. It emerged that popular asynchronous communication needs are text based and includes announcements and reminders. Announcements were popular with $86 \%$ of students suggesting that they would like to receive them through mobile phones. In this regard on students said, "Students prefer receiving quick and relevant information via mobile phone as it allows them to be kept up to date with any advancement that has been made with regard to certain courses ...”

The second popular need as suggested by the students was due date reminders for activities such as assignment submission with $76 \%$ of the suggestions. In this category, the least suggested need by the students was registration date reminders, which received $8 \%$ of the suggestions.

Communicating with students through their mobile phones is important in ODL because students do their studies in isolation and would be motivated if they receive some announcements or reminders from the lecturers. This is in line with Simpson [4] who suggested that mobile cellular phone can provide support to students to an extent of removing the feeling of isolation especially when used to provide essential learning information.

\section{3) Interaction needs}

In this category, five themes of needs emerged and were discussion forums (74\%), multiple choice assignments (60\%), structured question assignment submission (8\%), course survey feedback (4\%), and self-assessment (2\%). Discussion forums emerged as the most popular need and $74 \%$ of the students suggested it. Discussion forums were considered important by students because they allow them to follow topics of interest irrespective of geographical location and time. In this regard one student said, "Distance students are often not able to go to campus to collect materials and interact with fellow students and lecturers. ....Discussions can also be easily done on mobile phones with the use of chat software which is easily available."

The students suggested that discussion forums facilitate the establishment of relationships between students and lecturers, which in turn would assist the formation of study groups. Study groups are important in distance learning because they may help in bridging the distance between students and thereby removes the feeling of isolation when studying.

The other themes in this category were less popular to students, for example structured assignment question submission, course feedback and self-assessment. Even though students showed little interest in submitting structured assignment question through mobile phone, a number of students (60\%) suggested that they would like to do multiple choice assignment questions on their mobile phones.
In this category, students did not suggest other interaction activities such as interactive learning, data collection and information sharing. The reason for not suggesting other interaction needs is not clear; it is possibly that the students would not want to use mobile phones for such interactions.

The following section presents results from the fixedresponse survey which seeks to rank the needs according to their importance.

\section{B. Ranked mobile phone access needs}

This section presents the results of the analyzed quantitative survey. The importance of the needs was prioritized based on the importance of the need and frequency of access of the need. The results are presented based on these two dimensions.

\section{1) Ranking of the needs accoriding to their importance}

In the quantitative survey, students were asked to rank the importance of mobile phone information access needs that were identified from the first survey. A total of 84 students responded to the survey. The results of the first question are presented in Table II which depicts a list of the information needs, the responses per Likert category and the mean score. The mean score is used as a measure for ranking the importance of the needs and the top five needs are discussed in more detail.

The first five highly ranked needs based on the mean score rating are exam results (4.64), assignment results (4.63), assignment feedback (4.41), exam timetable (4.35), and due date reminders (4.28). The highest ranked need, exam results received $74 \%$ rating of very important and $0 \%$ not important on the Likert scale.

The second ranked need, assignment results received 70\% rating of very important and $0 \%$ not important on the Likert scale. The first five highly ranked needs confirm that students prefer to access smaller units of information that do not require intensive interaction with the device.

TABLE II. IMPORTANCE OF MOBILE PHONE NEEDS

\begin{tabular}{|c|c|c|c|c|c|c|}
\hline & $\begin{array}{l}\text { Not } \\
\text { Important }\end{array}$ & 2 & 3 & 4 & \begin{tabular}{|l|} 
Very \\
importa \\
nt
\end{tabular} & Mean \\
\hline Needs & \begin{tabular}{|l|}
$\%$ of \\
Total \\
\end{tabular} & \begin{tabular}{|l|}
$\%$ of \\
Total \\
\end{tabular} & \begin{tabular}{|l|}
$\%$ of \\
Total \\
\end{tabular} & \begin{tabular}{|l|}
$\%$ of \\
Total \\
\end{tabular} & \begin{tabular}{|l|}
$\%$ of \\
Total
\end{tabular} & \\
\hline 1. Exam results & $0 \%$ & $1 \%$ & \begin{tabular}{|l|}
$7 \%$ \\
\end{tabular} & $18 \%$ & $74 \%$ & 4.64 \\
\hline 2. $\quad$ Assignment results & $0 \%$ & $0 \%$ & $7 \%$ & $23 \%$ & $70 \%$ & 4.63 \\
\hline $\begin{array}{ll}\text { 3. } & \text { Assignment } \\
\text { feedback }\end{array}$ & $1 \%$ & $5 \%$ & $6 \%$ & $29 \%$ & $59 \%$ & 4.41 \\
\hline 4. $\quad$ Exam timetable & $1 \%$ & $5 \%$ & $15 \%$ & $15 \%$ & $64 \%$ & 4.35 \\
\hline 5. Due date reminders & $1 \%$ & $4 \%$ & $19 \%$ & $19 \%$ & $57 \%$ & 4.28 \\
\hline 6. $\quad$ Announcements & $4 \%$ & $6 \%$ & $7 \%$ & $34 \%$ & $49 \%$ & 4.2 \\
\hline $\begin{array}{ll}7 . & \text { Study material } \\
\end{array}$ & $5 \%$ & $7 \%$ & $15 \%$ & $12 \%$ & $61 \%$ & 4.19 \\
\hline 8. $\quad$ Lecture summaries & $2 \%$ & $11 \%$ & $18 \%$ & $25 \%$ & $44 \%$ & 3.95 \\
\hline 9. $\quad$ Course podcasts & $5 \%$ & $8 \%$ & $20 \%$ & $25 \%$ & $42 \%$ & 3.92 \\
\hline $\begin{array}{l}\text { 10. Tutorial and exam } \\
\text { venues }\end{array}$ & $2 \%$ & $9 \%$ & $24 \%$ & $27 \%$ & $38 \%$ & 3.9 \\
\hline 11. Discussion forums & $4 \%$ & $9 \%$ & $24 \%$ & $27 \%$ & $36 \%$ & 3.84 \\
\hline 12. Registration dates & $3 \%$ & $9 \%$ & $24 \%$ & $28 \%$ & $36 \%$ & 3.83 \\
\hline 13. Library access & $12 \%$ & $11 \%$ & $23 \%$ & $16 \%$ & $38 \%$ & 3.58 \\
\hline 14. Self-assessment & $14 \%$ & $6 \%$ & $19 \%$ & $37 \%$ & $24 \%$ & 3.5 \\
\hline 15. Student fees enquiry & $19 \%$ & $18 \%$ & $25 \%$ & $22 \%$ & $16 \%$ & 3 \\
\hline $\begin{array}{l}\text { 16. Campus maps and } \\
\text { directions }\end{array}$ & $29 \%$ & $24 \%$ & $20 \%$ & $15 \%$ & $12 \%$ & 2.56 \\
\hline
\end{tabular}


The five lowest ranked needs are registration dates (3.83), library access (3.58), self-assessment (3.5), student fees enquiry (3) and campus maps (2.56).

The least important of the needs namely campus maps received 29\% ranking of not important and $12 \%$ of very important. The second least need, student fees enquiry received $19 \%$ of not important and $16 \%$ of very important. Two of the needs, namely registration dates and students' fees enquiry involves minimum device interaction but still received low rankings. Notably both these items would not require frequent monitoring.

2) Ranking of mobile phone needs according to frequency of access

The students were asked to rank how often they would access a given need when implemented on a mobile system. The students were provided with a list of mobile phone information access needs and were supposed to rank their frequency of access on a Likert scale where 1(not often) and 5 (very often). Table III summarizes the findings and the top five needs are now discussed in more detail.

According to Table III the top five mobile phone information access needs that students would often access are assignment results (4), announcements (3.93), due date reminders (3.66), exam results (3.64) and assignments feedback (3.59).Comparing results in Table II and Table III, it can be seen that the ranking of importance are not the same as the ranking of frequency of access. Table III shows that the most frequently accessed need is assignment results. From Table II, assignment results were ranked in the second position. The reason for the high rating of assignment results may be due to the fact that students submit a number of assignments and the results determine their year mark, exam mark, exam admission and general progress in their studies.

The announcements need was ranked number 2 in the frequency of access table. This is against the $6^{\text {th }}$ position that it received on the importance of the need ranking in Table II. Taking a close comparative look on the scores across the Likert scale on Table II and III, Table II shows that $4 \%$ of students regarded this need as not important and $49 \%$ considered it very important. Table III shows that $6 \%$ of the students would not often access the need and $42 \%$ of the students would access the need very often. The results demonstrate that announcements are important and it would be useful if such functionality is implemented for mobile phone access. The high ranking of announcements on frequency of access may be due to the fact that there is a need for the fast dissemination of updates in the ODL context.

The need ranked number 3 is due date reminders. The need had a mean score of 3.66 with $39 \%$ of the students confirming that they would use due date reminders very often if implemented on a mobile phone system. While $7 \%$ of the students declared that they would not often access it if implemented on a mobile phone system. Comparing the due date reminders in Table III against those in Table II, due date reminders had a mean score of 4.28 and the importance of the need ranked at number 5 . Since the due date reminder is in the top five of both tables, it is a recommended need for mobile phone information access.

\begin{tabular}{|c|c|c|c|c|c|c|}
\hline & $\begin{array}{l}\text { Not } \\
\text { Often }\end{array}$ & 2 & 3 & 4 & $\begin{array}{l}\text { Very } \\
\text { Often }\end{array}$ & Mean \\
\hline Needs & $\begin{array}{l}\% \text { of } \\
\text { Total }\end{array}$ & $\begin{array}{l}\text { \% of } \\
\text { Total }\end{array}$ & $\begin{array}{l}\text { \% of } \\
\text { Total }\end{array}$ & $\begin{array}{l}\text { \% of } \\
\text { Total }\end{array}$ & $\begin{array}{l}\text { \% of } \\
\text { Total }\end{array}$ & \\
\hline 1. Assignment results & $4 \%$ & $5 \%$ & $25 \%$ & $20 \%$ & $46 \%$ & 4 \\
\hline 2. Announcements & $6 \%$ & $11 \%$ & $10 \%$ & $31 \%$ & $42 \%$ & 3.93 \\
\hline 3. Due date reminders & $7 \%$ & $14 \%$ & $24 \%$ & $16 \%$ & $39 \%$ & 3.66 \\
\hline 4. Exam results & $14 \%$ & $8 \%$ & $19 \%$ & $16 \%$ & $43 \%$ & 3.64 \\
\hline $\begin{array}{l}\text { 5. Assignment } \\
\text { feedback }\end{array}$ & $9 \%$ & $12 \%$ & $19 \%$ & $31 \%$ & $29 \%$ & 3.59 \\
\hline 6. Course podcasts & $17 \%$ & $8 \%$ & $16 \%$ & $23 \%$ & $36 \%$ & 3.53 \\
\hline 7. Discussion forums & $14 \%$ & $11 \%$ & $19 \%$ & $25 \%$ & $31 \%$ & 3.48 \\
\hline 8. Study material & $16 \%$ & $14 \%$ & $17 \%$ & $24 \%$ & $29 \%$ & 3.35 \\
\hline 9. Lecture summaries & $13 \%$ & $20 \%$ & $21 \%$ & $14 \%$ & $32 \%$ & 3.32 \\
\hline $\begin{array}{l}\text { 10. Tutorial and exam } \\
\text { venues }\end{array}$ & $16 \%$ & $13 \%$ & $29 \%$ & $1 \%$ & $26 \%$ & 3.21 \\
\hline 11. Self-assessment & $21 \%$ & $11 \%$ & $26 \%$ & $17 \%$ & $25 \%$ & 3.14 \\
\hline 12. Exam timetable & $13 \%$ & $17 \%$ & $34 \%$ & $15 \%$ & $21 \%$ & 3.12 \\
\hline 13. Library access & $27 \%$ & $14 \%$ & $22 \%$ & $16 \%$ & $21 \%$ & 2.89 \\
\hline 14. Registration dates & $20 \%$ & $22 \%$ & $27 \%$ & $13 \%$ & $18 \%$ & 2.87 \\
\hline 15. Student fees enquiry & $38 \%$ & $25 \%$ & $30 \%$ & $5 \%$ & $2 \%$ & 2.09 \\
\hline $\begin{array}{l}\text { 16. Campus maps and } \\
\text { directions }\end{array}$ & $48 \%$ & $27 \%$ & $11 \%$ & $3 \%$ & $11 \%$ & 2.04 \\
\hline
\end{tabular}

The need ranked at number 4 is the exam results. The mean score for the need was 3.64 with $43 \%$ of the students confirming that they would very often use the need when implemented on a mobile phone system. On the other hand, $14 \%$ of the students confirmed that they would not access the need often. Comparing the importance of the need ranking in Table II against the frequency of access ranking in Table III, in Table II the exam results need was ranked as the most important need with $74 \%$ of the students regarding it as very important. Even though the students find the need to be important their frequency of access to the need is ranked at number 4 because examinations only come once a semester. Since the need is in the top five on both tables, the need should be considered on a mobile phone system for HEI information access.

The need ranked at number 5 is assignment feedback. The need had a mean score of 3.59 with $29 \%$ of the students confirming that they would very often access the need when implemented on a mobile phone system. On the other hand 9\% of the students confirmed that they would not often access the need. Comparing the importance of the need ranking in Table II against the frequency of access ranking in Table III, assignment feedback was ranked as the $3^{\text {rd }}$ important need with a mean score of 4.41 and $59 \%$ of students regarding it as very important. In ODL, mobile phones can play an important role in providing students with timely feedback for student assignment. Mobile phone assignment feedback can be used for sending multiple choice answers or the assignment marks to the students. Since the need is in the top five rankings of both tables, it is an important need that is recommended for implementation on a mobile phone system for HEI student access. 
The lowest frequency accesses are exam timetable (3.12), library access (2.89), registration dates (2.87), student fees enquiry (2.09) and campus maps (2.04). Some of these needs are similar to those that were regarded as least important in table II except exam timetable. Exam timetable was considered as an important need and was ranked at number 4 with $64 \%$ of the students saying it's very important. The low ranking received by the exam timetable need in the frequency of access category may be due to the fact that exams are written once a semester and there is no need for continuously accessing the information throughout the semester.

\section{SUMMARY OF MOBILE PHONE INFORMATION NEEDS}

Table IV combines the Importance and Frequency scores from Tables II and III towards synthesizing a prioritized set of needs. Note that there are some needs that do not have frequency of access mean score. The needs are interaction activities and respondents were not asked to rate their frequency of access on these needs.

TABLE IV. SUMMARY OF MOBILE PHONE INFORMATION NEEDS

\begin{tabular}{|l|l|l|l|l|}
\hline & & & \\
& & & \\
& & & \\
\multicolumn{1}{|c|}{ Needs } & & & & \\
\hline Exam results & & & & \\
\hline Assignment results & 4.64 & 3.93 & $\mathrm{CN}$ & $\mathrm{R}$ \\
\hline Assignment feedback & 4.63 & 4 & $\mathrm{CN}$ & $\mathrm{C}$ \\
\hline Exam timetable & 4.41 & 3.59 & $\mathrm{CN}$ & $\mathrm{C}$ \\
\hline Due date reminders & 4.35 & 3.12 & $\mathrm{CN}$ & $\mathrm{R}$ \\
\hline Announcements & 4.28 & 3.66 & $\mathrm{CN}$ & $\mathrm{C}$ \\
\hline Study material & 4.2 & 3.93 & $\mathrm{CN}$ & $\mathrm{C}$ \\
\hline Lecture summaries & 4.19 & 3.35 & $\mathrm{CN}$ & $\mathrm{R}$ \\
\hline Podcasts/vodcast & 3.95 & 3.32 & $\mathrm{CN}$ & $\mathrm{R}$ \\
\hline Tutorial and exam venues & 3.92 & 3.53 & $\mathrm{CN}$ & $\mathrm{R}$ \\
\hline Discussion forums & 3.9 & 3.21 & $\mathrm{CN}$ & $\mathrm{C}$ \\
\hline SMS chatting & 3.84 & 3.48 & $\mathrm{CN}$ & $\mathrm{I}$ \\
\hline Telephone conversion & 3.27 & - & $\mathrm{CN}$ & $\mathrm{C}$ \\
\hline Sharing resources & 3.62 & - & $\mathrm{CN}$ & $\mathrm{C}$ \\
\hline Article download & 4.14 & - & $\mathrm{CN}$ & $\mathrm{R}$ \\
\hline Practice exam questions & 3.66 & - & $\mathrm{CN}$ & $\mathrm{R}$ \\
\hline Library access & 4.13 & - & $\mathrm{CN}$ & $\mathrm{R}$ \\
\hline Self-assessment & 3.58 & 2.89 & $\mathrm{AD}$ & $\mathrm{R}$ \\
\hline Student fees enquiry & 3.5 & 3.14 & $\mathrm{AD}$ & $\mathrm{I}$ \\
\hline Campus maps and directions & 3 & 2.09 & $\mathrm{AD}$ & $\mathrm{R}$ \\
\hline e-books & 2.56 & 2.04 & $\mathrm{AD}$ & $\mathrm{R}$ \\
\hline Registration dates & 3.85 & - & $\mathrm{AD}$ & $\mathrm{R}$ \\
\hline Abbreviations : & 3.83 & 2.87 & $\mathrm{AD}$ & $\mathrm{C}$ \\
\hline C=Communication; I=Interaction $; \mathrm{R}=\mathrm{Ressources}$ & & & \\
CN= Core need ; AN= Additional need & & & & \\
\hline & & & & \\
\hline
\end{tabular}

Table IV shows that the needs can be prioritized into two groups, the core needs (CN) and additional needs (AD). The core needs $(\mathrm{CN})$ are the primary needs that the students expect to have for mobile phone information access and interaction. The additional needs (AN) are secondary needs that are not considered essential for mobile phone access and interaction by the students.

Needs classified as core needs were those that facilitate students' essential interactions, access to resources and communication. These needs address some of the challenges related to ODL as now discussed in more detail.

In ODL, assessment feedback can take time to reach the students. The identified needs that can help in addressing student assessment problems include MCQ assignment submission, assignment feedback, practice exam questions, assignment results and exam results. In this category, selfassessment was identified as an additional need because students did not show much interest in it even though they showed much interest in practice exam questions.

Students in ODL are isolated and find it difficult to form study groups. Needs that can help in connecting students include SMS chatting, telephone conversation, sharing resources and discussion forums. These needs help students in forming study groups, which further necessitate the real time peer tutoring among the students.

In ODL context, lecturers are physically removed from students and can increase their presence by communicating with students frequently. The identified needs that can help in addressing the problem include sending announcements, alerts and reminders to the students.

ODL students are nomadic and require mobile access to information and resources. Students expressed that they need to have access to study material, lecture summaries, article download and podcasts/vodcasts. Resources that were identified as additional needs include library access, e-books and student fees enquiry.

Note that this study relates to mobile cellular phones usage and does not include PC-tablets. However, given the many similarities in the context of use, many findings have relevance for a wider set of mobile service provision. The prioritisation of the needs could help in selecting essential needs for designing and implementing mobile phone services for students at HEIs.

\section{VI.CONCLUSION}

The study gathered mobile phone information access needs of students at higher educational institutions and then prioritized the importance of those needs. The needs were categorized into communication needs, access to resources needs and interaction needs. The groupings of students' mobile phone information needs into these categories is based on the core uses of a mobile phone system as being informational, accessing resources or transactional $[1,9,10]$. This means mobile phones can be used for providing a variety of resources that are essential in solving the problem of digital difference [8] and other problems related to ODL such as student isolation, lack of interaction among students and the lecturers [4]. Some of the solutions to these problems were discussed in section $\mathrm{V}$. The needs that were identified as providing solutions to these problems were regarded as core needs (CN) in Table IV. Prioritizing the needs is not trivial since both the importance and frequency have to be considered and other factors like finance may also influence the prioritization. The contribution of the study is the identification of categories of information access and a set of prioritized information needs that can be used to inform strategic planning to assign and implement ICT resources ensuring optimum investment of HEIs' ICT resources and ensuring much needed synergies with 
the students' and faculty expectations. The findings are based on an ODL institution only but given the overall increase in student's mobility and mobile phone access the findings have relevance for residential universities too. Given the position of UNISA as the largest South African university the findings have potential for generalization towards other HEIs in South Africa. Further research will focus on refining the categories and capturing data with larger samples to verify the priorities within the categories.

\section{REFERENCES}

[1] J. Van Biljon, P. Kotzé and G. Marsden, "Motivational needs-driven mobile phone design," in INTERACT'07 Proceedings of the 11th IFIP TC 13 International Conference on Human-Computer Interaction, Rio De Janeiro, Brazil, 2007, pp. 523-526.

[2] H. Liebenberg, Y. Chetty and P. Prinsloo, "Student access to and skills in using technology in an open and distance learning context," The International Review of Research in Open and Distance Learning, vol. 13, pp. 250-268, 2012

[3] M. J. Lee and A. Chan, "Pervasive, lifestyle integrated mobile learning for distance learners: an analysis and unexpected results from a podcasting study," Open Learning, vol. 22, pp. 201-218, 2007.

[4] O. Simpson, Supporting Students in Online, Open \& Distance Learning. Routledge, 2013.

[5] B. Chipangura, J. Van Biljon and A. Botha, "Towards a mobile centric framework for inclusive sustainable interactions," Progressio: South African Journal for Open and Distance Learning Practice, vol. 34, pp. 161-182, 2012.

[6] B. Albrecht and J. A. Pirani. Massachusetts institute of technology: Transforming the campus experience with the MIT mobile web. Boulder, Co: EDUCAUSE Center for Applied Research,. MIT. 2009. Available: DOI:

http://www.educause.edu/ECAR/ResearchPublications/CaseStudies/1006 . (access 21 September 2013).

[7] D. R. Garrison, "Three generations of technological innovations in distance education," Distance Education Journal, vol. 6, pp. 235-241, September, 1985.

[8] A. Botha, "Mobile learning-an african perspective," in Satellite ICCR-09 Workshop on Innovative Mobile Technology \& Services for Developing Countries, Durban South Africa, 2010, pp. 1-8.

[9] B. Shneiderman, D. Byrd and W. B. Croft, "Clarifying search: A userinterface framework for text searches," D-Lib Magazine, vol. 3, pp. 1820, January. 1997.

[10] A. Broder, "A taxonomy of web search," ACM, New York USA, Tech. Rep. 36, Fall 2002. 2002.

[11] D. Rosen and C. Nelson, "Web 2.0: A new generation of learners and education," Computers in the Schools, vol. 25, pp. 211-225, October, 2008.

[12] K. Church and B. Smyth, "Understanding the intent behind mobile information needs," in Proceedings of the 13th International Conference on Intelligent User Interfaces, Sanibel Island, Florida, 2009, pp. 247-256.

[13] K. Church and N. Oliver, "Understanding mobile web and mobile search use in today's dynamic mobile landscape," in Proceedings of the 13th International Conference on Human Computer Interaction with Mobile Devices and Services, 2011, pp. 67-76.

[14] J. Waycott, S. Bennett, G. Kennedy, B. Dalgarno and K. Gray, "Digital divides? Student and staff perceptions of information and communication technologies," Comput. Educ., vol. 54, pp. 1202-1211, 2010.

[15] D. Kassab and X. Yuan, "Understanding the information needs and search behaviours of mobile users," Information Research, vol. 17, 2012

[16] L. Mockus, H. Dawson, S. Edel-Malizia, D. Shaffer, J. An and A. Swaggerty, "The impact of mobile access on motivation: Distance education student perceptions," World Campus Learning Design, 2011.

[17] M. Rutten and M. Mwangi, "Mobile cash for nomadic livestock keepers: The impact of the mobile phone money innovation (M-Pesa) on Maasai pastoralists in Kenya," Transforming Innovations in Africa: Explorative Studies on Appropriation in African Societies, vol. 11, pp. 79, 2012.
[18] C. A. Taylor, O. Anicello, S. Somohano, N. Samuels, L. Whitaker and J. A. Ramey. A framework for understanding mobile internet motivations and behaviors. Presented at CHI'08 Extended Abstracts on Human Factors in Computing Systems. 2008, Available: http://dub.washington.edu/djangosite/media/papers/1282-taylor.pdf. ( accessed 21 september 2013).

[19] Y. Cui and V. Roto. How people use the web on mobile devices. Presented at Proceeding of the 17th International Conference on World Wide Web. 2008, Available: http://dl.acm.org/citation.cfm?id=1367619 (accessed 21 september 2013).

[20] J. van Biljon and E. Dembskey, "Learning tools in resource constrained environments: Learning from e-learning in the time of m-learning," in ICT for Development: People, Policy and Practice. IDIA2011 Conference Proceedings, Lima, Peru, 2011, pp. 26-28.

[21] A. van Rooyen, "Integrating mobile technology into a distance education accounting module," in Proceedings of the 3rd International Conference on e-Learning, 2008, pp. 475.

[22] G. Jones, G. Edwards and A. Reid, "How can mobile SMS communication support and enhance a first year undergraduate learning environment?" ALT-J:Research in Learning Technology, vol. 17, pp. 201-218, November, 2009.

[23] J. R. Young. (Dec 2007). "LSU's Emergency- Notification System Malfunctioned.". Available: http://chronicle.com/blogs/wiredcampus/lsus-emergency-notificationsystem-malfunctioned/3560. (accessed 21 Septmber 2013).

[24] (October 2007). New university alert system tested across nation. DOI: http://www.collegiatetimes.com/stories/9770/new-university-alertsystems-tested-across-nation.(accessed 21 September 2013).

[25] J. Seeholzer and J. A. Salem Jr, "Library on the Go: A Focus Group Study of the Mobile Web and the Academic Library," College and Research Libraries, vol. 72, pp. 9-20, January, 2011.

[26] J. Richardson and J. Lenarcic, "SMS-push first and then students will pull administrative information in higher education?" in Proceedings of the 20th Australasian Conference on Information Systems, Australia, 2009, pp. 571-581.

[27] L. Naismith, "Using text messaging to support administrative communication in higher education," Active Learning in Higher Education, vol. 8, pp. 155, 2007.

[28] A. Moura and A. Carvalho, "Mobile Learning: Using SMS in Educational Contexts," Key Competencies in the Knowledge Society, pp. 281-291, 2010.

[29] S. L. Cheung, "Using mobile phone messaging as a response medium in classroom experiments," The Journal of Economic Education, vol. 39, pp. 51-67, 2008.

[30] Y. Park, "A pedagogical framework for mobile learning: Categorizing educational applications of mobile technologies into four types," The International Review of Research in Open and Distance Learning, vol. 12, pp. 78-102, 2011.

[31] D. Ng'ambi, "Collaborative questioning: A case of short message services (SMS) for knowledge sharing," in Advanced Learning Technologies, 2006. Sixth International Conference on, kerkrade, 2006, pp. 350-351.

[32] L. Butgereit, "Math on MXit: Using MXit as a medium for mathematics education," in Meraka INNOVATE Conference for Educators, Pretoria, 2007, pp. 1-13.

[33] J. Ritchie and J. Lewis, Eds., Qualitative Research Practice: A Guide for Social Science Students and Researchers. Sage Publications Ltd, 2003. 